\title{
Analytical Prediction on Flexural Response of RC Beams Strengthened with Steel Plates
}

\author{
Rendy Thamrin ${ }^{1, *}$ \\ ${ }^{1}$ Civil Engineering Department, Engineering Faculty, Andalas University, Indonesia
}

\begin{abstract}
An analytical prediction on flexural response of reinforced concrete (RC) beams strengthened with steel plates is presented in this paper. The method used in this study is based on theoretical momentcurvature determination which able to determine the complete response of reinforced concrete cross section subjected to monotonic flexural load. A computer program named Reinforced Concrete Cross Section Analysis (RCCSA) was developed and utilized to facilitate the computation process. Two types of flexural strengthening (tension-face and web bonded steel plates) were analyzed using the software and then compared with the experimental result. Result validation using existing available software was also carried out using Respone-2000 software. The comparison shows that the analytical model can be used to predict the flexural response of strengthened reinforced concrete cross section with a good accuracy.
\end{abstract}

\section{Introduction}

Structural damage often results after earthquakes occur. When heavy damage is sustained, the building must be demolished. However in many cases repair and strengthening can be a safe and more economical option if carried out appropriately. As regulations and insurance requirements become stricter, there is also a need to strengthen existing structures considered vulnerable to be to future earthquake damage to established standards. To this end a method to adequately calculate the flexural response of the intended strengthening reinforced concrete member is essential.

The development of strengthening methods for reinforced concrete (RC) structures is evolving rapidly as new construction materials are developed. The most recent strengthening innovation in civil construction is the use of fiber reinforced polymer (FRP)[1]. Many types of FRP are now available for strengthening structures including FRP plates and sheets. However, FRP is still expensive compared to traditional steel plates. Steel plates epoxy bonded to the surface of reinforced concrete members have been used for three decades to strengthen and repair reinforced concrete structures [2, 3]. This method appears to be an adequate and economical method for increasing the flexural and shear capacity of existing reinforced concrete members and is still in common use.

Software for structural analysis has also developed rapidly along with improvements in computer hardware. Until now, the finite element method has been the best-known method

* Corresponding author: rendythamrin@gmail.com 
available for structural analysis. However, modelling with finite element method is complex and cost consuming for a simple problem such as cross section analysis of reinforced concrete members.

The aim of this study is to develop software that can predict the full flexural response of strengthened reinforced concrete cross section rapidly and accurately. To develop the software, a method based on theoretical moment-curvature determination [4] was applied. Experimental study was also carried out and nine simple supported reinforced concrete beams consisted of three control specimens and six beams with flexural strengthening (bottom and web bonded plated) were tested. The test results are then used to validate the predictions from the software. In addition, existing available software named Respone-2000 (RESP.-2K ) [5] was used to verify the predictions from the developed software.

\section{Flexural analysis of cross section}

Theoretically, cross section analysis of reinforced concrete members is performed based on the relevant material constitutive equations and the assumptions of strain compatibility and equilibrium condition. It is also assumed that the tensile forces are carried by the tensile reinforcement while the compressive forces are carried by the concrete and the compression reinforcement. Two design methods are available in designing reinforced concrete i.e. elastic design and ultimate-strength design. However, because the reinforced concrete structures fail beyond the elastic limit, the ultimate-strength design method is more appropriate to use in this study. Fig. 1 illustrates the ultimate-strength design method using a rectangular reinforced concrete cross section with strain distribution, rectangular stress block, and resultant of internal forces. From this figure, the nominal moment capacity of the cross section is equal to:

$$
M_{n}=T s . z=C c . z
$$

In this study an analytical computation procedure based on theoretical momentcurvature determination adopted from literature [4] is used. Firstly, the reinforced concrete cross section is divided into a finite number of concrete and reinforcement layers as shown in Fig. 2.

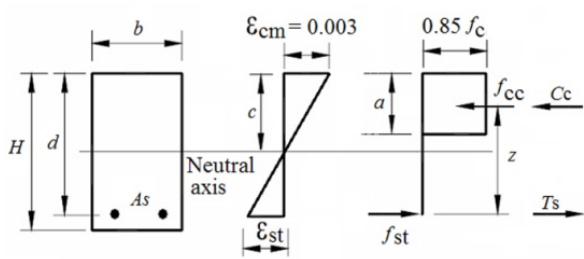

$\begin{array}{llll}\text { (a) Section } & \text { (b) Strain Distribution } & \text { (c) Stress (d) Forces }\end{array}$

Fig. 1. Stresses and internal forces in a reinforced concrete cross section.

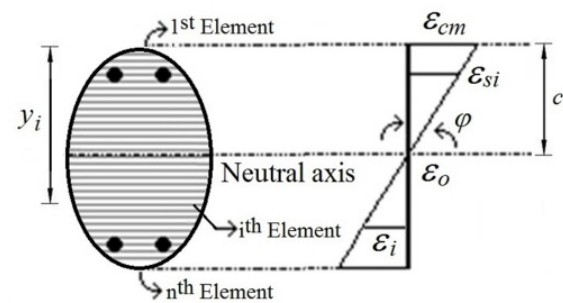

Fig. 2. An arbitrary cross section with assumed strain distribution.

The strain in element $i^{\text {th }}$ for each incremental step can be calculated using a given value of curvature, $\varphi$, as:

$$
\varepsilon_{i}=\varepsilon_{o}-\left(\varphi y_{i}\right)
$$


The corresponding stresses, $\sigma_{i}$, and internal forces, $F_{i}$, acting in each steel and concrete element with an area, $A_{i}$, are then calculated using the assumed stress-strain relationship of materials and the following equations:

$$
\begin{gathered}
\sigma_{i}=f\left(\varepsilon_{i}\right) \\
F_{i}=A_{i} \sigma_{i}
\end{gathered}
$$

The equilibrium of internal forces in the cross section is then obtained through an iterative procedure by estimating the axial strain, $\varepsilon_{o}$, for a given curvature which satisfies the equilibrium conditions written in Equation (5) for each increment of curvature.

$$
\sum F_{i} \approx 0
$$

where $F_{i}$ is the value of the force of each corresponding element. Finally, internal moment in the cross section can be calculated as:

$$
M=\sum F_{i} y_{i}
$$

Fig. 3 shows the detail of calculation process for a given value of curvature. The input data consists of cross section dimension, reinforcement data, material properties, and given curvature value. By using a given value of curvature and the stress-strain relationship (of concrete, steel reinforcement, and steel plate), the stresses and internal forces acting on each concrete element and reinforcement layer, and the steel plate can be calculated using Equation (3) and Equation (4). The iteration procedure is needed to obtain the neutral axis position which satisfied the equilibrium of the internal forces. This iteration step is started after the calculation of the internal forces for each concrete element and reinforcement layer.

The output for each incremental step is the moment versus curvature for the given value of curvature. The calculation process is stopped when the concrete at the top of compression zone crushed or passed the given limit value of compression strain. In this study, the value of maximum compression strain was assumed to be 0.005 . This method was implemented in RCCSA program (FORTRAN language) and a user-friendly interface (VB.Net language) was also developed to facilitate the input data and to visualize the results [6]. Fig. 4 shows the data input page of RCCSA software.

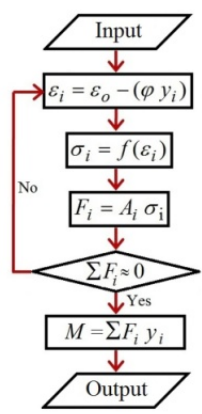

Fig. 3. Algorithm for theoretical moment-curvature determination

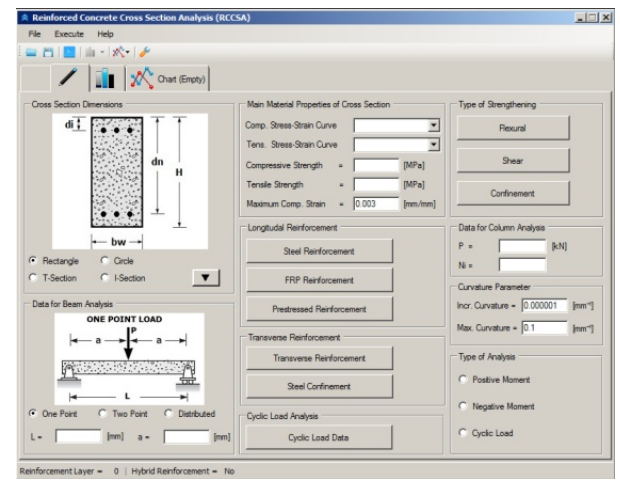

Fig. 4. The interface of RCCSA V4.3. 
An analytical load-deflection curve is obtained from moment-curvature distribution corresponding to each incremental step along the beam length and calculated using moment-area theorem. The deflection equation is:

$$
\delta=\int_{0}^{L / 2} x \varphi d x
$$

where: $\delta=$ deflection corresponding to the first moment of the area of the momentcurvature diagram for a half span of a simply supported beam of span $L$, evaluated with respect to beam support, and $\varphi=$ the curvature corresponding to each incremental step and obtained from moment-curvature relation calculated as explained previously.

Fig. 5 illustrates the assumed analytical model of strengthened reinforced concrete cross section (bottom and web bonded) with strain distribution, stress distribution and component internal forces. In this assumption, the steel plate acting as reinforcement and connection between the steel plate and the concrete are perfectly bonded. Hence, the strain distribution can be assumed to be linear along the height of the cross section.

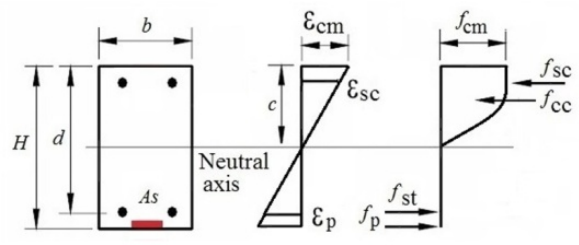

(a) Strain distribution and internal forces in cross section with bottom plate.

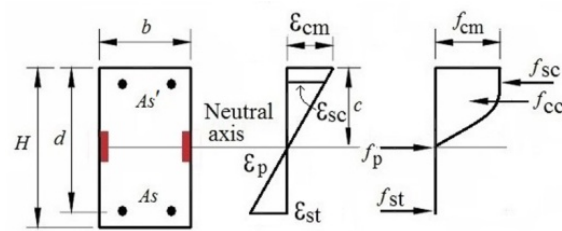

(b) Strain distribution and internal forces in cross section with web bonded plate.

Fig. 5. Assumed analytical model of strengthened reinforced concrete cross section.

The stress-strain relationship of concrete in compression used in this study is adopted from literature [7] and shown in Fig. 6(a). This model is a simple empirical equation and leads to efficient programing since only one parameter is needed to obtain the complete curve. The stress-strain relationship of concrete in tension used is linear model up to the tensile strength without a tension stiffening effect as shown in Fig. 6(a). The stress-strain relationship for steel bars employed in this study is adopted from the model proposed by Esmaeily and Xiao [8] and shown in Fig. 6(b). The stress-strain relationship for steel plates used in this study is similar to that used for steel bars as shown in Fig. 6(b).

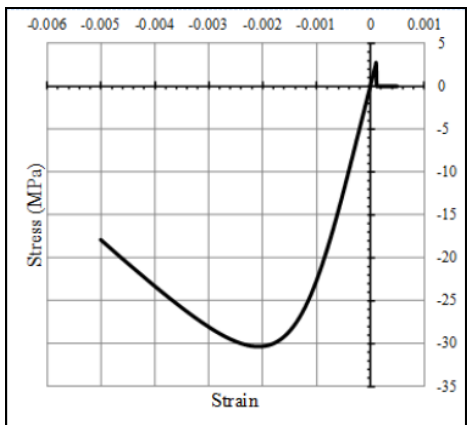

(a) Stress-strain relationship for concrete in compression and tension.

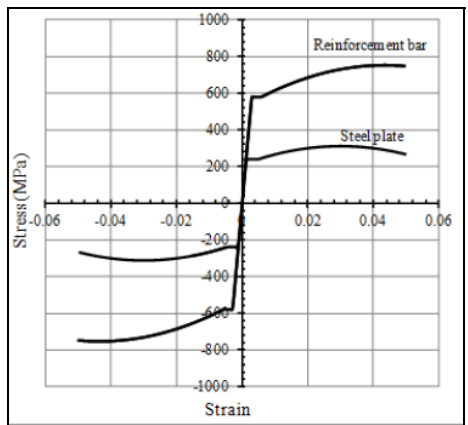

(b) Stress-strain relationship for steel reinforcement and steel plate.

Fig. 6. Stress-strain relationship used in analysis. 


\section{Experimental study}

Nine simply supported reinforced concrete beams with stirrups consisting of three control beams, three beams with a bottom steel plate, and three beams with web bonded steel plates were tested. Fig. 7 shows the configuration of the reinforced concrete beams strengthened using (a) bottom and (b) web bonded steel plates used in this experimental study. Loading position and dimension of the beam are shown schematically in Fig. 7. The total length of all beams was $2300 \mathrm{~mm}$; the clear span length was $2000 \mathrm{~mm}$, the shear span length $(L s)$ was $800 \mathrm{~mm}$ and the end anchorage length beyond the support $(L a)$ was $150 \mathrm{~mm}$. The cross section had dimensions of $125 \mathrm{~mm}$ width and $250 \mathrm{~mm}$ height.

Fresh concrete was ordered from the ready mix concrete company with the maximum aggregate size of $10 \mathrm{~mm}$ and target compressive strength of $30 \mathrm{MPa}$. Ten concrete cylinders with $150 \mathrm{~mm}$ diameter and $300 \mathrm{~mm}$ height were casted and tested to obtain the concrete compressive strength. The average concrete cylinder strength obtained from compression tests was $23 \mathrm{MPa}$ at age 28 days.

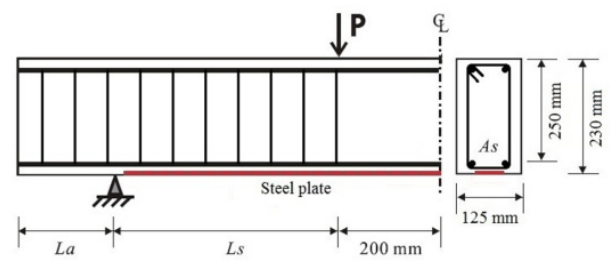

(a) Bottom plate.

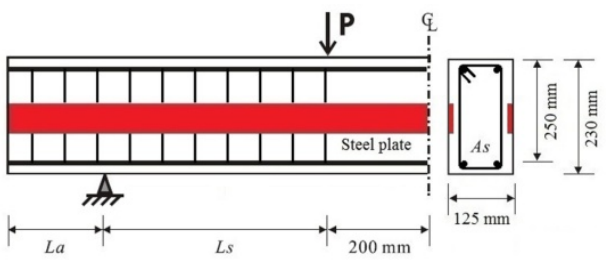

(b) Web bonded plated.

Fig. 7. Beam dimensions and position of steel plate.

Three ratios of longitudinal reinforcement $(0.9 \%, 1.4 \%$ and $2.5 \%)$ were used for control specimens and both types of strengthening. Deformed steel bars with $13 \mathrm{~mm}$ diameter and $580 \mathrm{MPa}$ yield strength were used as longitudinal reinforcement. The steel stirrups used were closed type with $10 \mathrm{~mm}$ diameter and $100 \mathrm{~mm}$ spacing with yield strength $391 \mathrm{MPa}$. Steel plates with $3 \mathrm{~mm}$ thickness and $250 \mathrm{MPa}$ yield strength were bonded to the surface of concrete beams. Each of these steel components had a modulus of elasticity of about 200 $\mathrm{GPa}$. The procedure used in applying the steel plates was to first make a groove on the beam surface. This method is identical to the near surface mounted strengthening technique. The steel plates were directly placed inside the grooves and slightly pressed along the whole length of the plate onto the adhesive. In this study, the low price commercially available epoxy adhesive was used to bond the steel plate to the concrete surface. Table 1 lists the details of steel reinforcement and plate used for strengthening.

Table 1. Beam reinforcement and strengthening data.

\begin{tabular}{|c|c|c|c|c|c|c|c|c|c|c|c|c|}
\hline \multirow[b]{2}{*}{ Specimen } & \multicolumn{4}{|c|}{ Tensile Reinforcement } & \multicolumn{4}{|c|}{ Compression Reinforcement } & \multicolumn{4}{|c|}{ Plate Strengthening } \\
\hline & $\begin{array}{c}\text { dia. } \\
(\mathrm{mm})\end{array}$ & $N$ & $\rho(\%)$ & $\begin{array}{c}f y \\
(\mathrm{MPa})\end{array}$ & $\begin{array}{c}\text { dia. } \\
(\mathrm{mm})\end{array}$ & $N$ & $\rho^{\prime}(\%)$ & $\begin{array}{c}f y \\
(\mathrm{MPa})\end{array}$ & Position & $\begin{array}{c}\text { Thickness } \\
(\mathrm{mm})\end{array}$ & $\begin{array}{l}\text { Width } \\
(\mathrm{mm})\end{array}$ & $\begin{array}{c}f y \\
(\mathrm{MPa})\end{array}$ \\
\hline $\begin{array}{l}\text { BK-01 } \\
\text { BK-02 } \\
\text { BK-03 }\end{array}$ & \multirow{7}{*}{13} & $\begin{array}{l}2 \\
3 \\
5\end{array}$ & $\begin{array}{c}0.99 \\
1.5 \\
2.5\end{array}$ & \multirow{7}{*}{580} & \multirow{7}{*}{13} & \multirow{7}{*}{2} & \multirow{7}{*}{0.99} & \multirow{7}{*}{580} & \multicolumn{4}{|c|}{$\begin{array}{l}\text { Control specimens without } \\
\text { strengthening }\end{array}$} \\
\hline BP-01 & & 2 & 0.99 & & & & & & Bottom & & & \\
\hline BP -02 & & 3 & 1.5 & & & & & & Bottom & & & \\
\hline $\mathrm{BP}-03$ & & 5 & 2.5 & & & & & & Bottom & 3 & 50 & 240 \\
\hline BT-01 & & 2 & 0.99 & & & & & & Web & & & \\
\hline BT-02 & & 3 & 1.5 & & & & & & Web & & & \\
\hline BT-03 & & 5 & 2.5 & & & & & & Web & & & \\
\hline
\end{tabular}


During the test, the beams were monotonically loaded until failure with two point loads using a $500 \mathrm{kN}$ capacity hydraulic jack. The load was applied by pumping the jack handle with a nearly constant and slow rate. The load was measured using a load cell positioned bellow the hydraulic cylinder and above the spreader beam as shown in Fig. 8(a). The deflections at midspan and at both of the loading points were measured using three linear variable displacement transducers (LVDTs) as shown in Fig. 8(a). The load cell and LVDTs were connected to a data logger to record the data. The cracks occurring during the test were examined and the values of crack loads were marked beside the crack line as shown in Fig. 8(b).

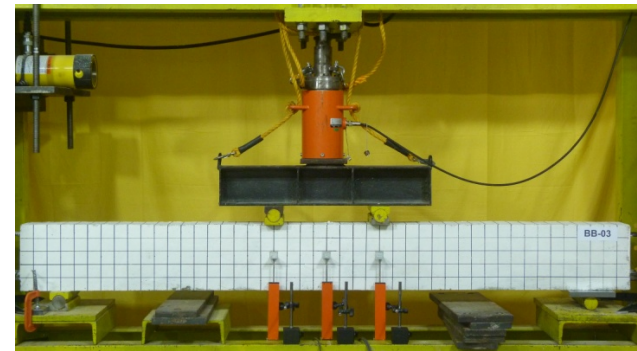

(a) Before the test.

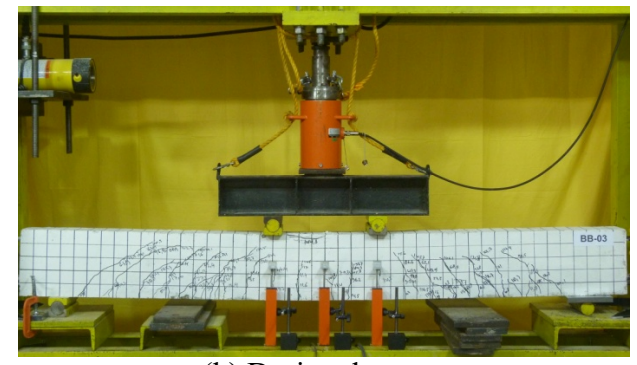

(b) During the test.

Fig. 8. Experimental set-up showing position of the equipment.

\section{Results and discussion}

The first crack for all the beams occurred in the midspan zone at an average load level of $8.5 \mathrm{kN}$. As the load increased the flexural crack appear and developed in the shear span zone. The flexural cracks located in the shear span zone then followed by the growth of diagonal shear cracks. The beams exhibited yielding of longitudinal steel as indicated by the flat part of load-deflection curves shown in Fig. 9 to Fig. 11. The yielding loads of longitudinal reinforcement occurred at different load levels depending on the reinforcement ratio. All the beams failed in flexural failure modes as indicated by crushing of concrete on the surface of the maximum compression zone.

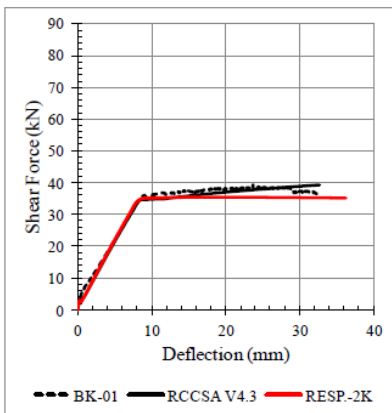

(a)

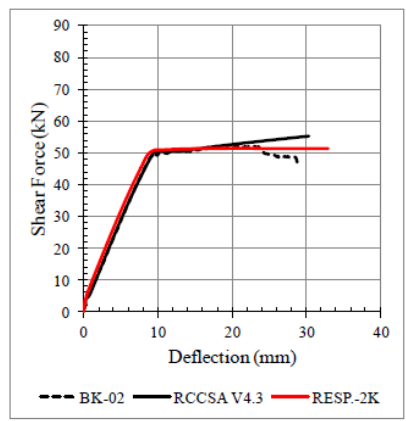

(b)

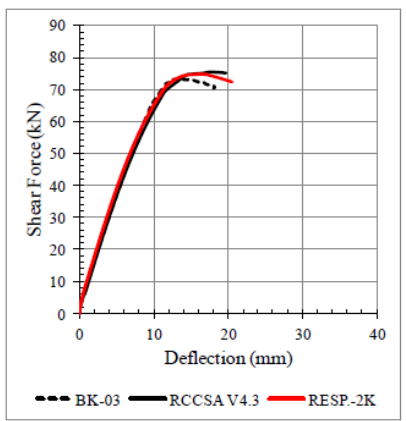

(c)

Fig. 9. Comparison between analytical and experimental results of beams without strengthening.

Experimental and analytical values of the first crack, yield, and failure loads are tabulated in Table 2. The ratios between experimental and analytical results were calculated to evaluate the accuracy of analytical model (Table 2). The comparison of the analytical (RCCSA V4.3 and RESP.-2K) and experimental midspan load-deflection curves are shown in Fig. 9 to Fig. 11. Fig. 9 shows that analytical calculation (RCCSA V4.3 and RESP.-2K) 
can accurately predict the general flexural behavior of the beams. However, in the case of the beam with the highest reinforcement ratio $(2.5 \%)$ and with web bonded plates, the analytical value is slightly smaller than the experimental value as shown in Fig. 11(c).

The deformation behavior of the reinforced concrete beam strengthened with steel plates depends on the bond performance between plates and the concrete surface both for bottom and web bonded members [3]. In three members, labeled BP-01, BP-03 and BT-02 debonding failure occurred before the beam reach its ultimate capacity as shown by the sharp drop in the load-deflection curve in Fig. 10(a), Fig. 10(c), and Fig. 11(b). After debonding occurred the load-deflection behavior of the beam was equivalent to that of the control beams without strengthening.

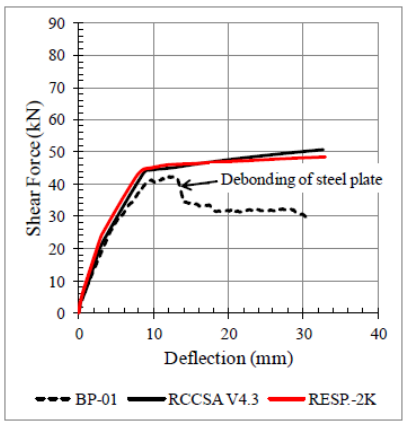

(a)

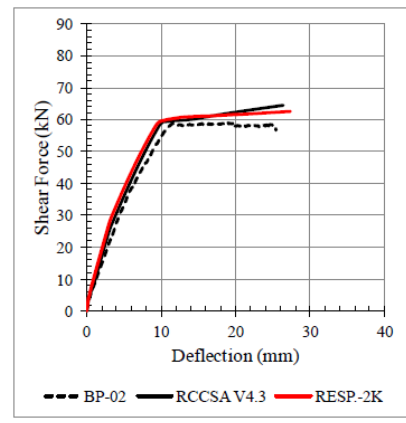

(b)

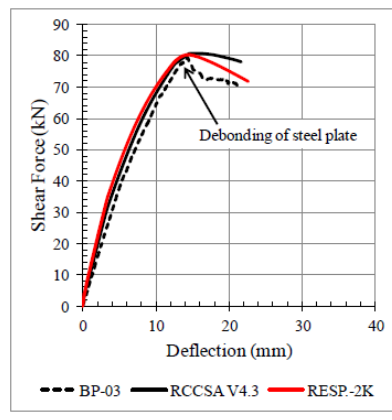

(c)

Fig. 10. Comparison between analytical and experimental results of beams strengthened with bottom plates.

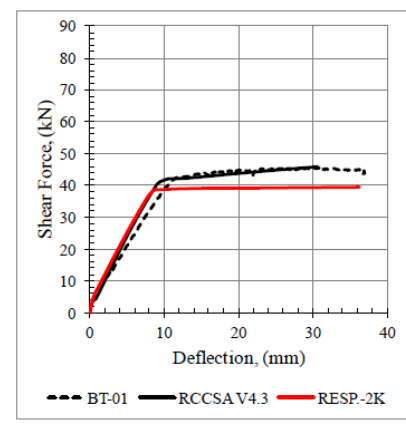

(a)

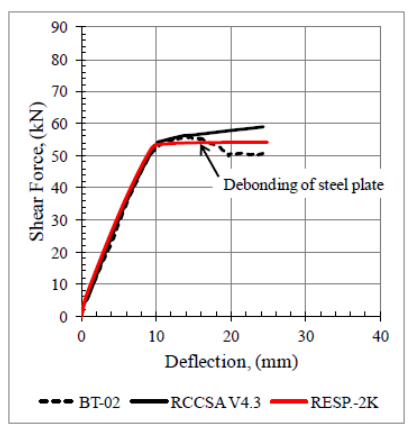

(b)

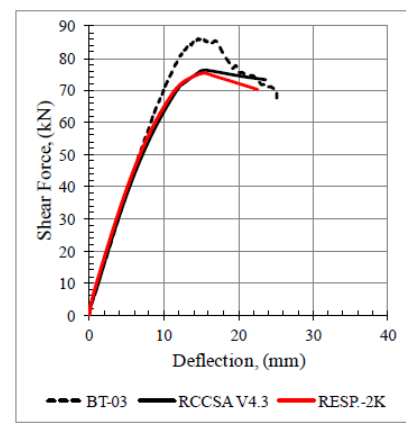

(c)

Fig. 11. Comparison between analytical and experimental results of beams strengthened with web bonded plates.

Both of analytical calculation can predict the general flexural behavior of the beams strengthened with side plated accurately as shown in Fig. 11 apart from one small discrepancy. At the peak load, the analytical result was approximately $10 \%$ smaller than the experimental value in the beam with the highest reinforcement ratio $(2.5 \%)$. The tensile reinforcement of all the beams reached the yield stress of $580 \mathrm{MPa}$ confirming the analytical predictions as shown in figures. The analytical model can accurately demonstrate the general behavior of concrete beams strengthened with steel plates.

As Fig. 9 to Fig. 11 confirm, the analytical model using theoretical moment-curvature determination predicts the flexural response of the beams through all ranges of elastic 
(before first crack and yielding of tensile reinforcement) and post-peak load. This model is faster to compute than conventional methods and is relatively simple to program.

Table 2. Experimental and analytical beam capacity values with comparison ratio.

\begin{tabular}{|c|c|c|c|c|c|c|c|c|c|}
\hline \multirow[b]{3}{*}{ Specimen } & \multicolumn{3}{|c|}{ Experimental } & \multicolumn{3}{|c|}{ Analytical } & \multicolumn{3}{|c|}{ Ratio } \\
\hline & $(1)$ & $(2)$ & (3) & $(4)$ & \begin{tabular}{|l|}
$(5)$ \\
\end{tabular} & $(6)$ & & & \\
\hline & $\begin{array}{c}\text { First crack load } \\
(\mathrm{kN})\end{array}$ & $\begin{array}{c}\text { Yield load } \\
(\mathrm{kN})\end{array}$ & \begin{tabular}{|c|}
$\begin{array}{c}\text { Failure load } \\
(\mathrm{kN})\end{array}$ \\
\end{tabular} & $\begin{array}{c}\text { First crack load } \\
(\mathrm{kN})\end{array}$ & $\begin{array}{c}\text { Yield load } \\
(\mathrm{kN})\end{array}$ & \begin{tabular}{|c}
$\begin{array}{c}\text { Failure load } \\
(\mathrm{kN})\end{array}$ \\
\end{tabular} & $(1) /(4)$ & $(2) /(5)$ & $(3) /(6)$ \\
\hline BK-01 & 8.9 & 34.6 & 38.6 & 3.9 & 34.2 & 39 & 2.3 & 1.0 & 1.0 \\
\hline BK-02 & 8.5 & 49.2 & 51.7 & 4.1 & 50 & 55 & 2.1 & 1.0 & 0.9 \\
\hline BK-03 & 6 & 69.8 & 70.5 & 4.4 & 62 & 75.02 & 1.4 & 1.1 & 0.9 \\
\hline BP-01 & 8.8 & 41.1 & 41.8 & 6.1 & 45 & 52 & 1.4 & 0.9 & 0.8 \\
\hline BP-02 & 9.3 & 58.6 & 58.6 & 6.3 & 61 & 66.9 & 1.5 & 1.0 & 0.9 \\
\hline BP-03 & 12.4 & 79.0 & 79.4 & 6.4 & 73 & 80 & 1.9 & 1.1 & 1.0 \\
\hline BT-01 & 6.9 & 42.3 & 45 & 5.2 & 43 & 47.7 & 1.3 & 1.0 & 0.9 \\
\hline BT-02 & 7.5 & 53 & 55.5 & 5.8 & 56 & 62.0 & 1.3 & 0.9 & 0.9 \\
\hline BT-03 & 6.5 & 82 & 85.9 & 6.5 & 68 & 75 & 1.0 & 1.2 & 1.1 \\
\hline
\end{tabular}

\section{Conclusions}

The analytical procedure for flexural analysis of strengthened reinforced concrete cross section beams is presented. The procedure adopted is based on the theoretical momentcurvature determination and was implemented into a computer program named RCCSA. Analytical predictions were compared to results of tests on nine reinforced concrete beams. The following conclusions can be noted from this study:

1. The analytical model can be used to predict the flexural behavior of the strengthened beams through all ranges of elastic and post-peak load, is fast to compute and relatively simple to program.

2. All the beams failed in flexural failure modes indicated by crushing of concrete on the surface of maximum compression zone between the two point loads in agreement with the analytical model.

3. The analytical model cannot predict the debonding failure as the parameters regarding the debonding failure load is not yet included in the model.

\section{References}

[1] H. Saadatmanesh, and A.M. Malek, Design guidelines for flexural strengthening of RC beams with FRP plates, J. of Composites for Construction, ASCE, 2(4), 158-164, (1998)

[2] R.N. Swamy, R. Jones, and J.W. Bloxham, Structural behaviour of reinforced concrete beams strengthened by epoxy-bonded steel plates, The Structural Engineer, $65 \mathbf{A}(2), 59$ $68,(1987)$

[3] D.J. Oehlers, M.S. Mohamed Ali, and W. Luo, Upgrading continuous reinforced concrete beams by gluing steel plates to their tension faces, J. of Structural Engineering, ASCE, 124(3), 224-32, (1998)

[4] R. Park, and T. Paulay, Reinforced Concrete Structures, John Wiley, New York, (1975)

[5] E.C. Bentz, Response 2000, retrieved on August 09, 2000 from http://www.ecf.utoronto.ca/ bentz/r2k.htm, (2000) 
[6] R. Thamrin, Reinforced concrete cross section analysis (rccsa) v4.3, Jurusan Teknik Sipil, Fakultas Teknik, Universitas Andalas, (2014)

[7] T.H. Almusallam, and S.H. Alsayed, Stress-strain relationship of normal, high strength and light weight concrete. Magazine of Concrete Research, 47(170), 39-44 (1995)

[8] A. Esmaeily, and Y. Xiao, Behavior of Reinforced concrete columns under variable axial loads: Analysis. ACI Structural J., 102(5), 736-744, (2005) 